\title{
Implications for the dynamic health of a glacier from comparison of conventional and reference-surface balances
}

\author{
W.D. HARRISON, ${ }^{1}$ L.H COX, ${ }^{2}$ R. HOCK, ${ }^{1,3}$ R.S. MARCH, ${ }^{4}$ E.C. PETTIT ${ }^{5 *}$ \\ ${ }^{1}$ Geophysical Institute, University of Alaska, 903 Koyukuk Drive, Fairbanks, AK 99775-7320, USA \\ E-mail: harrison@gi.alaska.edu \\ ${ }^{2}$ Department of Geophysical Engineering, Montana Tech, University of Montana, 1300 West Park Street, \\ Butte, MT 59701-8997, USA \\ ${ }^{3}$ Department of Earth Sciences, Uppsala University, SE-752 36 Uppsala, Sweden \\ ${ }^{4}$ US Geological Survey - Glaciology, 3400 Shell Street, Fairbanks, AK 99709-7245, USA \\ ${ }^{5}$ US Army Cold Regions Research and Engineering Laboratory, 4070 9th Street, Fort Wainwright, AK 99703-0170, USA.
}

\begin{abstract}
Conventional and reference-surface mass-balance data from Gulkana and Wolverine Glaciers, Alaska, USA, are used to address the questions of how rapidly these glaciers are adjusting (or 'responding') to climate, whether their responses are stable, and whether the glaciers are likely to survive in today's climate. Instability means that a glacier will eventually vanish, or at least become greatly reduced in volume, if the climate stabilizes at its present state. A simple non-linear theory of response is presented for the analysis. The response of Gulkana Glacier is characterized by a timescale of several decades, but its stability and therefore its survival in today's climate are uncertain. Wolverine seems to be responding to climate more slowly, on the timescale of one to several centuries. Its stability is also uncertain, but a slower response time would make it more susceptible to climate changes.
\end{abstract}

\section{INTRODUCTION}

How does a glacier respond to climate? In some textbook discussions (e.g. Paterson, 1994), it is implicitly assumed that the response is 'stable': if the climate remains steady, a steady state of the glacier with finite volume will finally be reached. However, such a simple view may lead to a major misunderstanding about the health of a glacier. Even if today's climatic regime were to stabilize permanently, there may be no such steady state, or only a state with drastically reduced volume, such as a cirque glacier would have. In these cases we consider the response to be 'unstable'. Notice that by this definition a glacier could experience an extended period of unfavorable climate and still have a stable response. Stability only requires the capability of reaching a steady state in a specified steady climate, regardless of whether the glacier would grow or shrink in the process. Also, a glacier could have a stable response in one climate regime but not in another. Finally, by 'unstable' we do not mean the onset of new mechanical effects such as surging, but only how the glacier will respond when there is no fundamental change in the physics of its flow.

The idea of ice-sheet instability is an old one (e.g. Böðvarsson 1955; Nye, 1960; Weertman, 1961), and a study of mass-balance data from Gulkana and Wolverine Glaciers, Alaska, USA, reminds us that instability may also occur in glaciers. Our focus here is on how instability may be identified in valley glaciers from mass-balance data, how rapidly they respond and what this implies for their future.

Our interpretation is unusual but quite simple. For each of the two glaciers we compare the conventional glacier-wide mass-balance series with the corresponding 'referencesurface' version. The latter is the balance that would exist

*Present address: Department of Geology and Geophysics, PO Box 755780, University of Alaska, Fairbanks, AK 99775-5780, USA. if the glacier surface had not changed from the initial or 'reference' configuration which it had at the beginning of a measurement program (Elsberg and others, 2001; Harrison and others, 2005). The effects of adjustment of the surface elevation and the terminus position, often called 'response', have therefore been removed. Comparison of the two balances thus gives information about how a glacier is responding to climate and, as we shall see, whether the glacier is likely to survive in today's climate.

It has been pointed out (Harrison and others, 2005) that while the conventional (or 'hydrologic') balance is the appropriate one for hydrologic applications, the referencesurface (or 'climatic') version is more useful for climate interpretation or as a proxy for climate in glacier response theory. Here the perspective is different in that both balances are used together to obtain information about the dynamics of glacier response.

\section{CONVENTIONAL AND REFERENCE-SURFACE BALANCES: REQUIREMENTS FOR DETERMINATION}

An analysis of the difference between the conventional and reference-surface balances requires that both be determined as accurately as possible. Here we give a summary of the requirements for determining each, and of some of the problems that may arise. Elsberg and others (2001) provide some further details and practical suggestions.

\section{Conventional balance}

It is common to determine conventional balance by some version of the glaciological method (Østrem and Brugman, 1991). Local balances $b$ are measured yearly (or seasonally) at points with measured coordinates and interpolated over the glacier surface. This enables the determination of the annual glacier-wide balance $B$ for a given year:

$$
B=\int b \mathrm{~d} A \text {, }
$$


where the integrand is evaluated at the glacier surface, and integration is over the map area $A$ of the glacier. (This and the following integrals are approximated by sums in practice.) For many glaciers, such as Gulkana and Wolverine, it is common to interpolate and extrapolate the local measurements with a function of balance $b$ vs elevation $z$ constructed from the local balances. This function is multiplied by the area-elevation distribution function $\gamma(z)$ as determined from the current map, and the product is integrated to give the conventional glacier-wide annual balance. In this case,

$$
B=\int b(z) \gamma(z) \mathrm{d} z
$$

where integration is over the elevation range of the glacier. The cumulative balance as a function of time is the sum of the annual balances. The approach needs to be checked or calibrated by comparing cumulative balance determined by the glaciological method with volume change measured by photogrammetric or other methods, realizing that they have their own limitations (e.g. Østrem and Haakensen, 1999).

There are several common problems in addition to the basic one of measuring local balance at a marker. The first problem is failure to update the map annually. Updating at irregular intervals leads to a balance series which is neither the conventional nor the reference-surface one, and therefore is difficult to interpret. One way to update the map is to interpolate a map for a particular year from maps made at greater intervals. A second problem is failure to measure the coordinates of the markers each year, particularly their elevations. This prevents accurate determination of the areaelevation curve. A third problem is failure to calculate the cumulative balance series correctly. The common practice is to add conventional annual balances in meters (water equivalent) per year. The proper procedure is to add glacier-wide annual balances in volume units directly $\left(\mathrm{m}^{3}\right.$ w.e. $\left.\mathrm{a}^{-1}\right)$ without division by glacier area. This is mathematically different, and correct when area is continuously changing, as it is in fact. All of these issues have been taken into account in the reduction of the Gulkana and Wolverine data.

These effects may seem small in a given year, but they are systematic and over time can lead to significant errors, not only in the difference between conventional and referencesurface balances, but in the conventional balance itself.

\section{Reference-surface balance}

Reference-surface balances can be determined without making any additional measurements. For simplicity it is usually best to choose the reference surface as that of the glacier during the first year of a measurement program, at least if a good map from then exists. The reference-surface glacier-wide annual balance $B^{\prime}$ for a given year is

$$
B^{\prime}=\int b^{\prime} \mathrm{d} A^{\prime}
$$

where the integral is taken over the map area $A^{\prime}$ of the reference surface, and $b^{\prime}$ is the balance on the reference surface for the year of interest. The reference-surface analogue of Equation (2) is

$$
B^{\prime}=\int b^{\prime}(z) \gamma^{\prime}(z) \mathrm{d} z
$$

where $\gamma^{\prime}(z)$ is the area-altitude distribution function for the reference surface, as found from the corresponding map. This is never changed. The balance-elevation function $b^{\prime}(z)$ is the same as that used for the conventional balance in the same year, $b(z)$. To understand this, it is helpful to realize that for any given map point (as defined by its horizontal coordinates) the surface elevations and therefore the two balances will be different. Reference-surface cumulative balance as a function of time is found by summing the annual balances. This would be the cumulative balance if the glacier surface did not change.

If the local reference-surface balances $b^{\prime}$ are also of interest, they can be extrapolated from each measured $b$. Extrapolation from the actual surface to the referencesurface elevation is done at the locations of the measured points, using the known difference in surface elevations and the balance-elevation gradients. The latter are estimated from the balance-elevation curve which was constructed for the conventional balance. The resulting $b^{\prime}$ are simply the local balances corrected for surface-elevation change.

The problems associated with the determination of the reference-surface glacier-wide balance tend to be similar to those associated with the conventional balance. However, the use of a single map in the reference-surface case is a huge simplification, because annual map updating is not required. Although not necessary for the present applications, it is a good idea to report the reference-surface map when reporting a reference-surface balance series, because the series depends upon it.

The procedures outlined here produce a balance that is corrected for both area and elevation changes, although it is possible to calculate a balance that is corrected for map area change alone (personal communication from M.B. Dyurgerov, 2008). We suggest that the latter be given a name, such as the 'reference-area' balance, to indicate that it is not the same thing.

\section{CONVENTIONAL AND REFERENCE-SURFACE BALANCES: GULKANA AND WOLVERINE GLACIERS}

Gulkana Glacier is located at $63^{\circ} 16^{\prime} \mathrm{N}, 145^{\circ} 25^{\prime} \mathrm{W}$ in the central Alaska Range in interior Alaska. Wolverine is in a more maritime climate at $60^{\circ} 25^{\prime} \mathrm{N}, 148^{\circ} 54^{\prime} \mathrm{W}$ in the Kenai Mountains. The locations are shown in Figure 1, along with topographic information. Both glaciers had an area of roughly $17 \mathrm{~km}^{2}$ in the late 1990s, but Gulkana is at higher elevation and is more complex. In recent years both glaciers typically have had accumulation-area ratios of $0.5-0.6$. The connections between balance and climate for these glaciers have been investigated by Hodge and others (1998), Rasmussen and Conway (2004) and Josberger and others (2007).

Balance measurements on these glaciers are conducted by the US Geological Survey using a variation of the glaciological method (see Mayo and others, 1972, 2004). At present, there are only three measurement points per glacier, but the results have been checked with more extensive stake networks and photogrammetric data. The cumulative balances from the most recent data reduction from 1966 to 1999 for Gulkana and from 1966 to 2002 for Wolverine are shown in Figure 2. They have been updated slightly from those reported by Cox (2002), Cox and March (2004) and L.H. Cox (unpublished data). During these periods Gulkana lost about $12 \%$ of its area, and Wolverine about $7 \%$.

For Gulkana Glacier, over a 25 year period the average thickness changes measured by glaciological and photogrammetric methods are consistent at the $1 \mathrm{~m}$ level (Cox and March, 2004), and recent mapping is consistent with data 


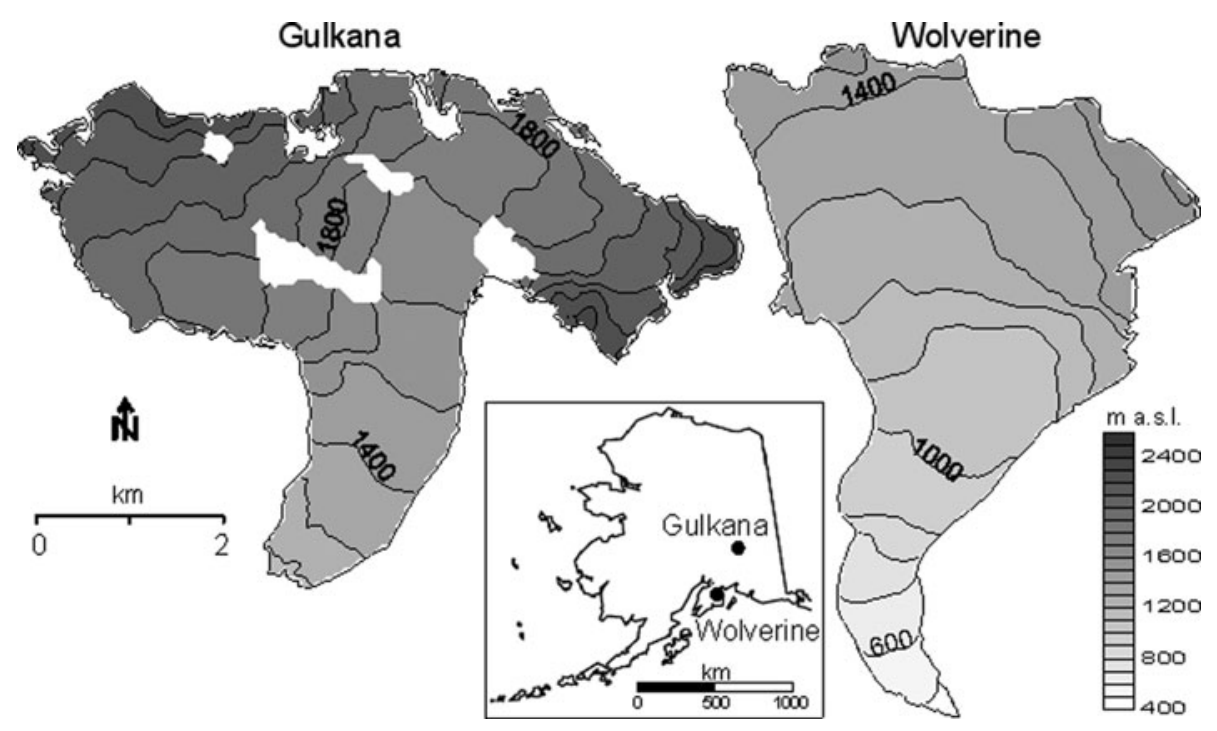

Fig. 1. Locations and topographic maps. The maps for Gulkana and Wolverine glaciers are from 1993 and 1979 respectively.

from airborne elevation profiling (Echelmeyer and others, 1996). The error in the reference-surface balance is poorly known but could be similar. This is roughly a quarter of the difference between the two balances at the end of the measurement period. It is likely that the errors in the two balances are correlated in the sense that the difference between them tends to be preserved, which is important as we shall see. Notice that the difference between the cumulative balances was already about a third of the conventional balance at the end of the measurement period, and has probably been increasing rapidly since then.

The consistency between the glaciological and photogrammetric methods is poorer for Wolverine Glacier, about $2 \mathrm{~m}$. Both glaciers suffer from uncertainties in the topography at the beginning of the measurement period.

\section{THEORY}

The difference between the conventional and referencesurface balances depends upon three things: the state of the glacier at the beginning of the measurement period, the climate history since then, and the response characteristics (or 'dynamics') of the glacier. One of the parameters characterizing the dynamics is a timescale which is thought to have the same order of magnitude as the duration of longterm mass-balance programs, several decades. This would mean that enough time has passed for difference in the two balances to develop, which is a necessary condition for an analysis of the difference between them. The general requirement is significant change in the glacier surface during a period on the order of one timescale.

The simplest version of glacier response theory is characterized by a single parameter, the timescale $\tau_{V}$ (e.g. Jóhannesson and others, 1989; Elsberg and others, 2001; Harrison and others, 2001). It is conceptually simplest to think of the balance quantities in this theory as being expressed in ice-volume equivalent units, but any consistent units will serve. We have

$$
\frac{\mathrm{d} \Delta V}{\mathrm{~d} t}+\frac{\Delta V}{\tau V}=\dot{B}^{\prime}
$$

in which $t$ is time, $\Delta V$ is the cumulative balance, and $\dot{B}^{\prime}$ is
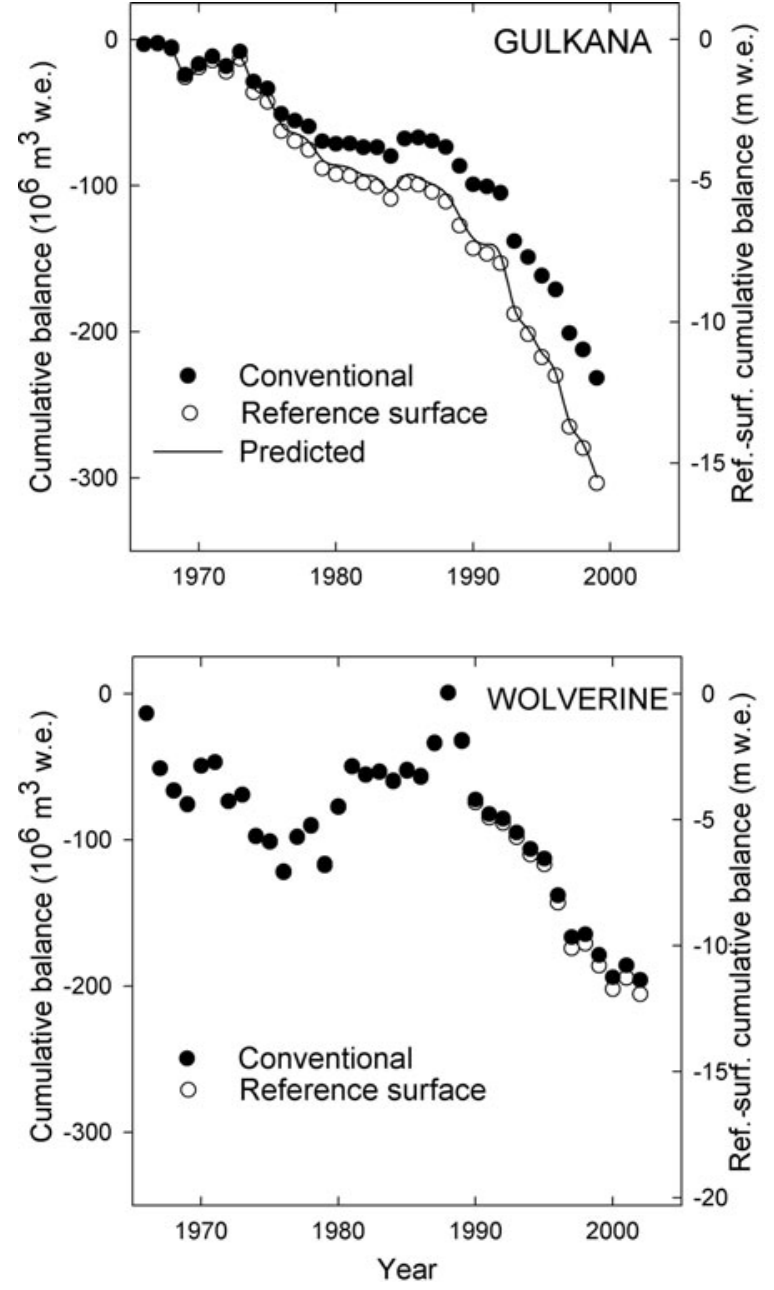

Fig. 2. Conventional and reference-surface cumulative balances for Gulkana and Wolverine Glaciers. The righthand scales refer to the map area of the reference surface. The Gulkana curve represents a fit to the reference-surface data. 


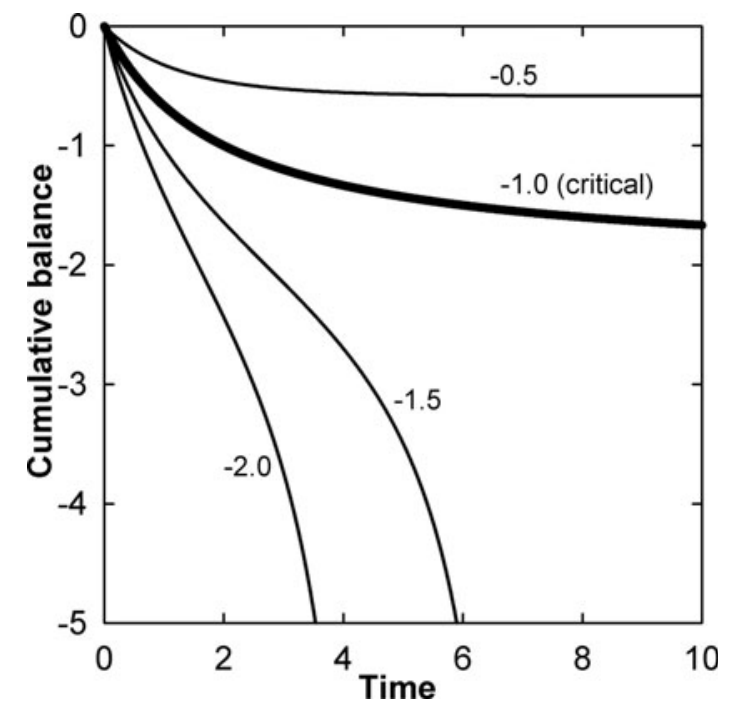

Fig. 3. Response to several steady climate scenarios. Each curve is labeled by its reference-surface balance rate normalized to the magnitude of the critical value. Thus the curve labeled -1.0 is the response when the reference-surface balance rate has the critical value. It is seen that a steady state is not approached if the reference-surface balance rate is more negative than this. See text for other units.

the reference-surface balance rate (the slope of the corresponding curves in Figure 2), as approximated by the annual value. $\dot{B}^{\prime}$ is a proxy for climate, which can be thought of as forcing the response of $\Delta V$. The timescale $\tau_{V}$ is defined by

$$
\tau_{V}=\frac{1}{\frac{-\dot{b}_{t}}{H}-\dot{g}}
$$

in which $\dot{b}_{\mathrm{t}}$ is the balance rate at the terminus, $\dot{g}$ is the gradient of the balance rate with elevation, and $H$ is a thickness scale. The first term in the denominator, which is positive because $\dot{b}_{\mathrm{t}}$ is negative, accounts for the stabilizing effect of terminus change on the response; the second accounts for the destabilizing effect of surface elevation change (Harrison and others, 2001).

The basis for Equation (5) is that mass continuity can be satisfied when the state of a glacier is specified by its map area and volume alone. This requires that the balance rate varies linearly with elevation (Harrison, unpublished information), although the problem can be minimized by taking suitable averages (Elsberg and others, 2001). The second requirement is that changes are small, as is suggested by the linearity of Equation (5). The third requirement is that perfect plasticity holds, by which we mean that there is a unique functional relationship between glacier map area and volume. In this case, one can think of area adjusting instantaneously to volume changes. Perfect plasticity does not fully capture the effect of the initial condition of the glacier on the response. To do this requires a more complicated theory with two more parameters (Harrison and others, 2003).

The most obvious limitation for our application is the requirement of small changes. A generalization is therefore useful. Notice in Equation (6) that $\tau_{V}$ depends upon the balance rate at the terminus, $\dot{b}_{\mathrm{t}}$. This is taken to be constant in linear theory, but in fact it changes as a glacier retreats or advances, by an amount which depends upon the bed slope and the balance-rate gradient at the terminus. As a result, $\dot{b}_{t}$ depends upon the terminus position. This can be characterized by the map area $\Delta A$ (strictly speaking, the area referenced to its initial value), or upon $\Delta V$ because of the connection plasticity implies between them. As a result, the effect can be accounted for by adding to Equation (5) a term proportional to $\Delta V^{2}$. There are several other effects contributing to a $\Delta V^{2}$ term, one of which is the change of the thickness scale $H$ with glacier size. Since $H$ is a proportionality factor relating $\Delta V$ and $\Delta A$ (e.g. Harrison and others, 2001), a variable $H$ implies a non-linear relationship between these quantities, which would be significant in the establishment of volume-area scaling relationships. At any rate, the net result of such effects is that we add a term $C \Delta V^{2}$ to Equation (5), realizing that $C$ is a constant which depends upon a variety of parameters. A second-order theory valid for moderate changes is thus obtained:

$$
\frac{\mathrm{d} \Delta V}{\mathrm{~d} t}+\frac{\Delta V}{\tau_{V}^{\prime}}+C \Delta V^{2}=\dot{B}^{\prime}
$$

where $\tau_{v}^{\prime}$ is as defined by Equation (6), but with the parameters in it evaluated at their initial (reference-state) values.

Equation (7) is a simple generalization of Equation (5), but it captures, at least approximately, the sort of unstable behavior which is probably common in nature. Consider the scenario in which the climate is stable $\left(\dot{B}^{\prime}=\right.$ const $\left.\equiv \dot{B}_{\mathrm{s}}^{\prime}\right)$, and look to see if a steady-state solution $\Delta V_{\mathrm{s}}$ to Equation (7) results. For this we set $\mathrm{d} \Delta V / \mathrm{d} t=0$ and obtain a quadratic equation for $\Delta V_{\mathrm{s}}$. It has the solution

$$
\Delta V_{\mathrm{s}}=\frac{-1+\sqrt{1+4 C\left(\tau_{V}^{\prime}\right)^{2} \dot{B}_{\mathrm{s}}^{\prime}}}{2 C \tau_{V}^{\prime}}
$$

(There is another solution, but it is metastable (see Weertman, 1961) and thus less interesting.) A solution to Equation (7) will exist only if the argument of the radical is nonnegative. This means that there is a critical 'threshold' value of $\dot{B}_{\mathrm{s}^{\prime}}^{\prime}$ which we call $\dot{B}_{\mathrm{c}^{\prime}}^{\prime}$ given by

$$
\dot{B}_{\mathrm{c}}^{\prime}=-\frac{1}{4 C\left(\tau_{V}^{\prime}\right)^{2}} \text {. }
$$

This is a useful result because it is a criterion for the onset of unstable response. By this we mean that if the climate stabilizes in a way that the reference-surface balance rate is more negative than given by Equation (9), there will be no stable finite volume $\Delta V_{\mathrm{s}}$ and the glacier will disappear, at least according to this theory. However, it is worth keeping in mind that at some point the volume loss will become large, and even this theory will become inaccurate because it is valid only for moderate changes. Thus a real glacier may undergo large changes without entirely vanishing by the time the theory fails; failure could be because of complex bed topography, for example.

Integration of Equation (7) produces a series of response curves for the constant-climate scenario as shown in Figure 3. Each curve is labeled by the reference-surface balance rate in units of the magnitude of the critical value, $\left|\dot{B}_{c}^{\prime}\right|$. (Time is normalized by $\tau_{v}^{\prime}$ and cumulative balance by $\left|\dot{B}_{c}^{\prime}\right| \tau_{V}^{\prime}$.) Thus the curve labeled -1.0 is the response when the reference-surface balance rate has the critical value. A steady state is not approached if the 
reference-surface balance rate is more negative than this. When the resulting instability is well developed, the glacier shrinks at an increasing rate. One can think of this occurring because the stabilizing effect of retreat is dominated by the destabilizing effect of surface lowering, although separating these effects may be tenuous when non-linear effects are important.

\section{APPLICATION TO GULKANA AND WOLVERINE GLACIERS}

\section{Gulkana Glacier}

Given the conventional balances, we used Equation (7) to find the best least-squares fit to the reference-surface balances. The linear theory, Equation (5), gives a significantly poorer fit. The result is shown by the curve in Figure 2 . The best fit is obtained with $\left(\tau_{V}^{\prime}, C\right)=\left(28,8.4 \times 10^{-5}\right)$, where the units of $\tau_{V}^{\prime}$ are years and those of $C$ are (years $\mathrm{m}^{3}$ w.e. $)^{-1}$. From these values Equation (9) predicts a critical reference-surface balance rate of $-3.8 \times 10^{6} \mathrm{~m}^{3}$ w.e. $\mathrm{a}^{-1}$. Dividing by the initial (reference) area of $19.3 \times 10^{6} \mathrm{~m}^{3}$ gives a critical specific referencesurface balance rate of $-0.20 \mathrm{~m}$ w.e. $\mathrm{a}^{-1}$.

The accuracy of these numbers was investigated with a series of sensitivity tests based upon the expected errors. It was found that scaling both balance series by the same amount did not have a large effect on the results, particularly on $\tau_{v}^{\prime}$. However, scaling only one balance was serious, to the extent that while about 30 years for $\tau_{V}^{\prime}$ was still the best value, it could be larger by several decades. The effect on the critical balance rate was larger; even its sign could be changed. These are extreme tests, because as noted above we expect a tendency for the difference between the two balances to be preserved.

It is conservative to say in summary that a minimum value of the timescale is about 30 years, but it could be several decades longer. The critical reference-surface balance rate is not well constrained by the data, and it may be that the failure of perfect plasticity to capture fully the effect of the initial state of the glacier is also an issue. This means that we have not been able to say with confidence whether the response of Gulkana Glacier has been stable or unstable in the sense of Equation (9). It is nevertheless instructive to demonstrate what our best (although not reliable) value of $-0.20 \mathrm{~m}$ w.e. $\mathrm{a}^{-1}$ for the critical reference-surface balance rate would mean. During the last three intervals of data, this balance rate was about $-1.3 \mathrm{~m}$ w.e. $\mathrm{a}^{-1}$, which would mean that by then, and indeed over most of the data record, the response would have been unstable.

\section{Wolverine Glacier}

We see in Figure 2 that the relationship between the two balance series for Wolverine Glacier is entirely different from Gulkana's in that the two balances are almost the same. One possible reason is that the conventional balance at Wolverine Glacier, unlike that at Gulkana, experienced some positive years during the first half of the record, and as a result one might expect comparatively little change in the surface and therefore in difference between the two balances. During the second half of the record, the change in the conventional balance was strong and monotonic, but there was only half as much time for difference in the two balances to develop. It turns out that the difference between the balances is too small for extraction of any information about the second-order term in Equation (7), and therefore the critical balance rate for instability. The difference between the balances can be understood in terms of a timescale $\tau_{V}^{\prime}$ somewhat larger than that of Gulkana Glacier, one to a few centuries. Independently of the issue of stability vs instability, a larger timescale would imply that Wolverine Glacier adjusts more slowly to climate than does Gulkana, and therefore would be prone to larger losses in a specified climatic regime.

\section{DISCUSSION AND CONCLUSIONS}

Although we have not been able to determine convincing values of the critical reference-surface balance rate for either glacier, Gulkana seems to be responding more rapidly to climate conditions than Wolverine. However, the data suggest that the response of Gulkana, at least, could be unstable in the sense of Equation (9), which requires the reference-surface balance rate to be more negative than the critical value. This would indicate the probability of large future change if the present climate persists.

It is interesting that the failure of a glacier to adjust significantly does not mean that it is not flowing. This is because of the two ways a glacier adjusts, as noted earlier. The first is by change in the surface elevation, which tends to destabilize or 'magnify' response, and the second by change in the terminus position, which tends to stabilize it. A glacier could thus flow, at least in priciple, so that adjustment of the surface elevation and terminus position have equal and opposite effects, although separating them may be tenuous in a non-linear regime.

Many ice masses throughout the world are probably in an unstable regime. Extreme examples are a substantial icefield near Yakutat and Brady Glacier, both in southeast Alaska. They are now so low in elevation that they receive no net accumulation, nor are they likely to in any plausible future climate scenario. Lacking an accumulation area, their disappearance is all but certain. Gulkana and Wolverine Glaciers still have significant accumulation areas. An interesting question is whether under some conditions instability in ice masses can be reached while they still have significant accumulation areas, as is possible in ice sheets. This speculation is suggested by early work (e.g. Weertman, 1961) and by our own calculations dealing with plastic glaciers on sloping beds with steep headwalls.

Issues pertaining to the rate of response of a glacier to climate, whether the response is stable or unstable, and whether a glacier is likely to survive in the present climate, are all components of what we call the 'dynamic health' of a glacier. It can be at least partially judged by comparing conventional and reference-surface balance series when both balances are accurately determined. It is clear that dynamic effects, even when the physics of flow is unaffected, can seriously complicate the relationship between balance and climate.

\section{ACKNOWLEDGEMENTS}

We are grateful for the valuable comments of A. Rasmussen, A. Arendt, and A. Fountain. Part of this work was performed while one of us (W.H.) was a guest at the Antarctic CRC, University of Tasmania. 


\section{REFERENCES}

Böðvarsson, G. 1955. On the flow of ice-sheets and glaciers. Jökull, 5, 1-8.

Cox, L.H. 2002. Comparison of geodetic and glaciological mass balance techniques, Gulkana Glacier, Alaska. (MSc thesis, University of Alaska, Fairbanks.)

Cox, L.H. and R.S. March. 2004. Comparison of geodetic and glaciological mass-balance techniques, Gulkana Glacier, Alaska, U.S.A. J. Glaciol., 50(170), 363-370.

Echelmeyer, K.A. and 8 others. 1996. Airborne surface profiling of glaciers: a case-study in Alaska. J. Glaciol., 42(142), 538-547.

Elsberg, D.H., W.D. Harrison, K.A. Echelmeyer and R.M. Krimmel. 2001. Quantifying the effects of climate and surface change on glacier mass balance. J. Glaciol., 47(159), 649-658.

Harrison, W.D., D.H. Elsberg, K.A. Echelmeyer and R.M. Krimmel. 2001. On the characterization of glacier response by a single time-scale. J. Glaciol., 47(159), 659-664.

Harrison, W.D., C.F. Raymond, K.A. Echelmeyer and R.M. Krimmel. 2003. A macroscopic approach to glacier dynamics. J. Glaciol., 49(164), 13-21.

Harrison, W.D., D.H. Elsberg, L.H. Cox and R.S. March. 2005. Correspondence. Different mass balances for climatic and hydrologic applications. J. Glaciol., 51(172), 176.

Hodge, S.M., D.C. Trabant, R.M. Krimmel, T.A. Heinrichs, R.S. March and E.G. Josberger. 1998. Climate variations and changes in mass of three glaciers in western North America. J. Climate, 11(9), 2161-2179.
Jóhannesson, T., C. Raymond and E. Waddington. 1989. Time-scale for adjustment of glaciers to changes in mass balance. J. Glaciol., 35(121), 355-369.

Josberger, E.G., W.R. Bidlake, R.S. March and B.W. Kennedy. 2007. Glacier mass-balance fluctuations in the Pacific Northwest and Alaska, USA. Ann. Glaciol., 46, 291-296.

Mayo, L.R., M.F. Meier and W.V. Tangborn. 1972. A system to combine stratigraphic and annual mass-balance systems: a contribution to the International Hydrological Decade. J. Glaciol., 11(61), 3-14.

Mayo, L.R., D.C. Trabant, and R.S. March. 2004. A 30-year record of surface mass balance (1966-95) and motion and surface altitude (1975-95) at Wolverine Glacier, Alaska. USGS Open File Rep. 2004-1069.

Nye, J.F. 1960. The response of glaciers and ice-sheets to seasonal and climatic changes. Proc. R. Soc. London, Ser. A, 256(1287), 559-584.

Østrem, G. and M. Brugman. 1991. Glacier mass-balance measurements. A manual for field and office work. Saskatoon, Sask., Environment Canada. National Hydrology Research Institute. (NHRI Science Report 4.)

Østrem, G. and N. Haakensen. 1999. Map comparison or traditional mass-balance measurements: which method is better? Geogr. Ann., 81A(4), 703-711.

Paterson, W.S.B. 1994. The physics of glaciers. Third edition. Oxford, etc., Elsevier.

Rasmussen, L.A. and H. Conway. 2004. Climate and glacier variability in western North America. J. Climate, 17(9), 1804-1815.

Weertman, J. 1961. Stability of ice-age ice sheets. J. Geophys. Res., 66(11), 3783-3792. 